\title{
What is an international language?
}

\author{
JACQUELINE LAM KAM-MEI interviews \\ MICHAEL A. K. HALLIDAY on language and linguistics, \\ English and Chinese, Singaporean and Hong Kong English, and \\ machine translation
}

[This interview is reproduced with permission (and minor adaptations) from The Hong Kong Linguist, No. 21, 2000.]

I FIRST learned that Michael Halliday speaks fluent Putonghua in June 1996, when I was one of the conveners of the conference 'Language analysis and description: Applications in language teaching', jointly organized by the Hong Kong University of Science \& Technology and the then Lingnan College (now Lingnan University) in Hong Kong. At that conference, the chairperson announced at Professor Halliday's plenary that this was one of the last conference invitations he would accept. It was a pleasant surprise, therefore, in October 1999, to receive Lingnan's announcement that Prof. Halliday would be in Hong Kong to receive an honorary doctorate and would be giving a lecture there entitled 'What is an international language?' We met in the early morning of 29 September at the Coffee Shop of the Furama Hotel.

JLKM What are the criteria for calling a language 'International'?

MAKH There are at least two senses of the term 'international language' - as well as its original meaning of an artificial language like Esperanto. First, languages that are originally regional may become more widely spoken, like Malay-Indonesian, Arabic, Spanish and Portuguese. Secondly, languages may become international second languages, like English, French, or Russian. The difference is not very sharp; English spreads in both ways. What sorts of functions does an international language have to serve? Why one language rather than another, in this context? One factor that is relevant today is the shift from a goods-andservices economy to an information economy. Information is made of language; so whatever language has become the main medium for software, for information services, is going to be international in that very important sense. It may be that at any one time one language will predominate, because this is very much a global activity; at the moment, it is English. This doesn't mean that it's always going to be English. Chinese is obviously a very strong candidate as an alternative.

JLKM But many people have said that Chinese is a difficult language to learn. This is especially true in the case of Cantonese.

MAKH Spoken Chinese is not really so difficult to learn; but the writing is. The Chinese language is not particularly difficult compared to others; but it uses a writing system which takes a long time to learn, because of the characters. If people want Chinese to become an international language, they will have to find better ways to teach it; it is generally not very well taught to foreigners. There are really two choices, for international purposes. The first is to romanize the script, by using a system such as Pinyin (although Pinyin is not necessarily the best system for international use). The other is to find better ways of teaching the characters; but this will always take time, and adults usually haven't got much time to spare.

In any case, when you teach Putonghua to foreigners, you use a roman transcription to get them going. The same applies to Cantonese: you teach through the roman script first. Then you switch to characters later, when they know the language reasonably well. It's quite different when Cantonese speakers learn 
Putonghua; they know the characters already, and use Pinyin to help them remember the right pronunciation. But this is not the case for foreigners. It's pretty well impossible for foreigners to learn to speak Chinese (Putonghua or Cantonese) if you insist on teaching them characters at the start. I know too many examples of intelligent and hard-working people simply failing to master the Chinese language because they have been wrongly taught. Nonnative speakers can't be expected to learn characters at the same time as learning the language (after all, Chinese children speak the language fluently by the time they start to read and write). In teaching Chinese to foreigners as in any other teaching situation - you need to develop practices which take account of the students' previous learning experience.

JLKM During your talk at Lingnan, you mentioned that Chinese, English and Spanish are used by more people than any other languages. Is English the most effective of the three in areas like business, science and technology? If so, how can non-native English speakers be confident that the English they speak will be understood by people from other parts of the world?

MAKH If English is international, it must be intelligible to speakers around the world; it doesn't matter whether they are native or nonnative speakers. Anyone who is using it internationally needs to maintain this intelligibility. My point was that you need a model. If you are in a country such as India or Singapore, where English has an official status and there is a locally standardized kind of English, which is perfectly intelligible internationally, you can use that as your model. We know perfectly well that not everyone will attain the model; but you still have that as your target. It is what the teachers aim for with their students.
MICHAEL HALLIDAY, English linguist and grammarian, was born 1925 in Leeds, Yorkshire. Both his parents were teachers; his father, Wilfrid J. Halliday (1889-1975), after retiring as a headmaster, played a major part in compiling material from the North of England in Harold Orton's 'Survey of English Dialects'. Halliday studied Chinese language and literature at the University of London, and linguistics at postgraduate level, first at Peking University and Lingnan University (at that time in Guangzhou), then at Cambridge (Ph.D. 1955; published as 'The Language of the Chinese "Secret History of the Mongols", Blackwell, 1959). In 1963 he became Director of the Communication Research Centre, University College London, where he directed two influential projects: one in the description of scientific English, the other a language education project that led, among other outcomes, to 'Breakthrough to Literacy', a program for teaching children to read. In 1965, he became Professor of Linguistics in the University of London; in 1972 Professor of Linguistics at the University of Illinois, Chicago; and in 1976 Foundation Professor of Linguistics at the University of Sydney, where he remained until retiring at the end of 1987. In 1981, he gained the Russell Award from the National Council of Teachers of English (U.S.A.), and in 1986 he held the Lee Kuan Yew

Distinguished Visitor position at the National University of Singapore.

In the 1960s he worked in applied linguistics, co-authoring with Angus McIntosh and Peter Strevens 'The Linguistic Sciences and Language
Teaching' (Longman, 1964). His interests include children's language development, spoken and written language, stylistics, computational linguistics, discourse analysis, scientific language, social variation in language, Chinese language and linguistic theory, and English semantics and grammar. His contributions to English language studies include 'Intonation and Grammar in British English' (Mouton, 1967), [with Ruqaiya Hasan] 'Cohesion in English' (Longman, 1976), and 'An Introduction to Functional Grammar' (Arnold, 1985, 1994). His approach, known as 'systemic grammar' and 'systemic functional linguistics', is orientated towards applications, emphasizing the functional organization of language, and the ways in which social action, interpersonal settings and rhetorical mode influence selections made. As he put it, "meaning is a product of the relation between the system and its environment". In his work on general theory of language, Halliday has asserted the unity of syntax and lexicon in a lexicogrammar. A comprehensive bibliography of his writings can be found at:

http://minerva.Ling.mq.edu.au/Resources/Virtual Library/Bibliography/sysbibliography.html

JACQUELINE LAM KAM-MEI teaches English at the Language Centre of the Hong Kong University of Science and Technology. She has an M.A. and a Ph.D. in applied linguistics from the University of Exeter, and is editor of the bi-annual journal The Hong Kong Linguist (published by the HK branch of the Institute of Linguists). 
The model is what maintains the international quality of the language. Now in Hong Kong, we may regard English as a foreign language. I don't think there's a recognized standard of 'Hong Kong English' in the way there may be in India. So you probably need to use a native variety as a model; traditionally, here, it has been British English, for obvious reasons. Some parts of the world tend to follow British English, some parts tend to follow North American; I don't think this is anything to worry about. But it is important to maintain the chosen variety as a model. This does not mean that you insist that everyone should sound like a Briton or an American. But in order to preserve intelligibility, you need to set this as the target that people are actually aiming for.

JLKM As regards British English, would it be sensible to take Received Pronunciation (RP) as a model?

MAKH I don't get too hung up on RP because the British don't use it now very much. I talk a kind of international English which is not strictly RP in many ways, but it's good enough. Modern teaching materials that come from British sources (and British teachers) do not usually adhere rigidly to a model of RP or Queen's English or whatever you want to call it. They vary quite a bit - but within limits, and that seems to me to be a perfectly sound practice for Hong Kong. On the other hand, plenty of people who go to the United States will come back speaking American English. That's fine too.

JLKM Should I take the BBC as a pronunciation model for my students? And, what variety of spelling should we use?

MAKH The BBC is very good because it has a lot of English varieties. I didn't grow up speaking RP; my dialect was very different. So I like a bit of variety in the English being spoken - but, as I say, with variations which stay within the limits. The BBC is very good in that respect because it gives students a good range [within] British English. In that general area, Australian and New Zealand English, which are essentially descendants from the British variety rather than the American variety, will also serve very well. There are very good materials from Australia which teachers can use. As regards spelling, I know some people and some publishers are very fussy about this, but I don't think we need to be. It's just useful to be aware of the difference between British and American spellings.

JLKM In your work on English texts, you have asserted the unity of syntax and lexicon within lexicogrammar, pointing out that meanings are expressed through three interrelated functions: the ideational, the interpersonal, and the textual. Can such a view also apply to translation from English to Chinese and vice versa? And if so, how?

MAKH Yes. They are general concepts, part of a theory of language, which means that they apply to all languages. In fact there is now a lot of work on Chinese grammar in these terms, published in China in books and journals using this model. I think you can keep them in mind in the translation process because it is useful to be able to ask regarding a particular text whether you have succeeded in carrying over meanings of these different kinds into other languages. Translators traditionally have been much better at carrying over ideational meanings than interpersonal meanings, which in some ways are more difficult because more fluid, less determinate, and more varied. As regards whether translators should translate literally or just translate the meanings of a text; it largely depends on the purpose of the translation: who you are doing it for and what kind of text it is. There is no single answer to that and there is no single right way to tackle the problem. What is difficult for translators is to maintain the kind of variation within the language that you find in many kinds of text, which is not an easy task. Such a problem arises particularly in translating certain kinds of fiction or drama, where the original may have a lot of variation between different registers. Speakers become more or less colloquial, more or less informal, more or less technical, more or less local, regional and so on, and the text will often explore and exploit these differences to very great effect and it is not easy to carry over in translated text. The best way to overcome such a situation is to know both languages very well. The essential thing is when we are translating from English to Chinese, we need to be sensitive to these variations in English, then ask ourselves, given the purpose and context of the translation: Do we want to maintain all these variants in the translated text? Translators sometimes get confused with the term 'cultural background'. Culture, however, 
does not necessarily mean traditional Chinese or British culture. For example, if you are translating some scientific text, the culture is 'modern science', which is universal. But obviously if you are translating Hongloumeng (The Red Chamber) into English, it does matter what the context of the Chinese culture was. The question is what cultural background we want. 'Culture' is often misinterpreted as 'traditional culture'; but it does not always mean that. It may mean, as I said, some modern 'international culture': finance or science or ecology, and that's what matters.

JLKM As a language teacher, I am curious to learn whether it is true, as some people argue, that there is a grammar in written languages but no grammar in spoken languages as such or grammar of a rather different kind. How would you respond to such a view?

MAKH Let me say strongly - that is complete nonsense. There is as much grammar in the spoken language as in the written, otherwise it wouldn't work. Grammar is [concerned] with language functions. So spoken language is every bit as grammatical - highly structured, richly structured, and every bit as complex as written language in its grammar. But it is complex in different ways. Between written Chinese and spoken Chinese, or spoken English and written English, there will be systematic differences. Some people may say that in order to bring out all these differences, let us, as it were, start again and write a totally different grammar for the spoken language. Now, you can do this, and it will then bring out special features in a very clear way. On the other hand, in some ways, it's misleading, because they are not two different languages; they are still one and the same language. The boundary between the spoken and written form is fluid. We cannot just say "here is written, and here is spoken". There are all kinds of intermediate states. The spoken/written distinction is just one variable, and I would still think, for educational purposes, it's more useful to maintain the unity - to say: this is one language, whether it's written or spoken, but there are special features that characterize the written and special features that characterize the spoken. The view of spoken languages as composed of just colloquialism and therefore having no grammar is totally mistaken. This has done a lot of harm in teaching.
JLKM With your profound knowledge of the Chinese language and from your long experience working with Chinese speakers of English, what aspects do you think most of the Chinese in Hong Kong and Mainland China need to focus on to make themselves more comprehensible for, and effective with, English speakers?

MAKH On the whole, I think both in Hong Kong and in the rest of China the level of English is pretty good, although it does tend to go down as it spreads out. I have noticed this in China: more people are learning English, and so the standard goes down in the sense that, while in the past there were only a selected few who learned English so they spoke it very well, now the same limited number are still speaking it very well but there are many others learning who don't manage to speak it properly. Unfortunately they tend to get jobs as tour guides! The problem is that they are not taught how to pronounce the language. Of course, you can't really separate whether the problem lies in pronunciation or in sentence structure, because there is always a trade-off between the two: if your performance is less good in one aspect but good in another aspect, the one can compensate for the other.

However, your pronunciation obviously has to be above a certain threshold; otherwise it doesn't matter how good your sentence structure is, you won't be understood. I think what's happened is that, in training much larger numbers of English teachers, people - not just in China; I think it's true generally around the world - have forgotten the importance of training them in phonetics. When I was first trained it was a requirement that you should be taught phonetics, as a science: you would be taught how to produce and to listen to sounds, and also how to teach the sounds to students. I have the impression that this is not done now, or not done nearly as well as it used to be. This is one of the problems with teaching English on a large scale: it is important to include phonetics in course design, in the training of teachers, but phonetics is best taught face to face and requires a great deal of time and effort. I don't know whether, in Hong Kong or in Mainland China, there is discussion about the need for people who are professionally trained in phonetics and the teaching of pronunciation. But it is a resource which should not be forgotten.

JLKM There is something that has bothered 
me ever since the NET [Native English Teacher] scheme started in 1998. In your opinion, is employing native English speakers to teach in local schools an effective way to improve students' proficiency in English?

MAKH I think it is a good idea to have a mixture. The native speakers are desirable because they provide a model. As I was saying before, that doesn't mean you expect your students to sound like American or British speakers; but it makes sure that the distance does not become too great. This is not just a question of pronunciation; you need them as models for the grammar and discourse as well. On the other hand you don't want to be exclusively dependent on native speakers, because an important component of the teachers' experience is that they themselves have had to study the language. Also, there is a difference between teaching a language to small children and teaching it to adolescents or adults. When you are teaching young children native speakers have the advantage, because children soon realize if the teachers' own knowledge is defective. When you are teaching adolescents or adults, I would say that, for beginners, you need teachers who speak the students' first language - Cantonese, in the case of Hong Kong; whereas when they get more advanced, native speakers can be extremely valuable: British, Australian, North American and so on. It is the combination of the two that is most effective.

JLKM Do you think that certain syntactic and vocabulary items used by people in Hong Kong and China can be regarded as an acceptable variety, on a par with, say, Singaporean and Malaysian English?

MAKH This is what I was saying before: there are certain areas like Singapore and India, and some regions of Africa and the Pacific, where you can recognize an NVE, one of the 'New Varieties of English' (contrasting with the OVEs, the 'Old Varieties of English' like British and North American). I don't think this term really applies in Hong Kong. But wherever there is a standard, of any kind, you will get this phenomenon that linguists call a 'lectal continuum': some proportion of people will attain the standard variety, in a form that is totally intelligible, and there will be others all the way along the scale, to the point where no outsider can understand them. (You find
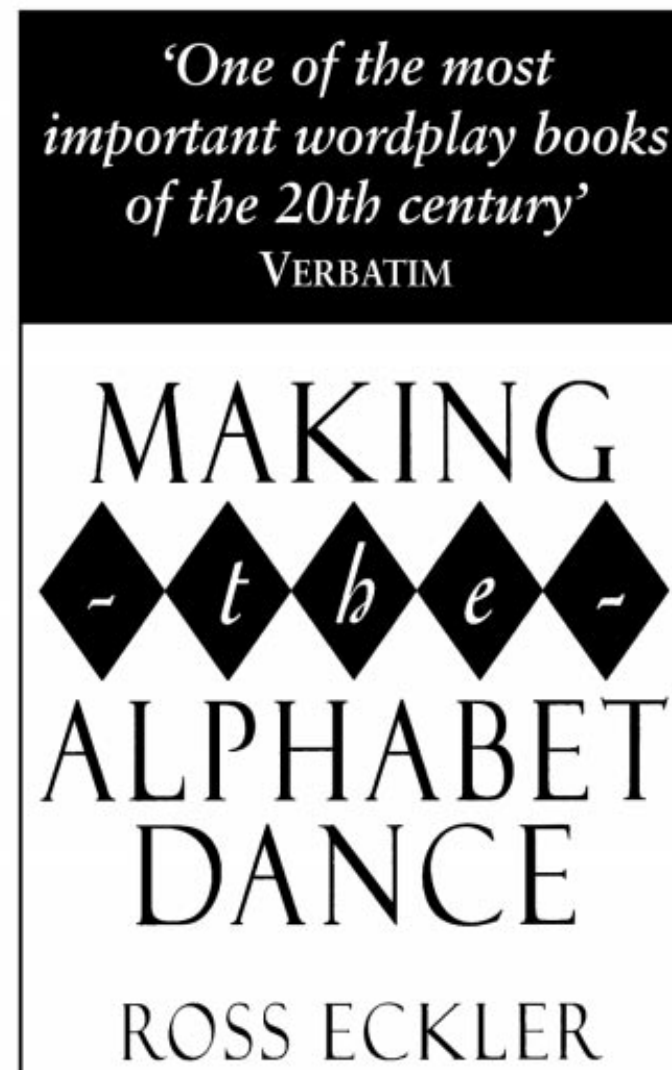

If you are a

crossword-puzzle solver, punster, anagrammatist, palindrome-maker, dictionary-scourer, Scrabble player, code-breaker or you just love the intricacies of the English language this is the book for you.

Paperback RRP $£ 12.99$

www.panmacmillan.com

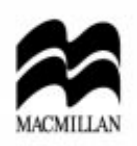

SPECIAL OFFER to readers of

English Today - only f10.99, P\&P free. Call 01256302699 to order and quote GLR 565 . 
the same thing with Putonghua: some people in Hong Kong speak it just like Beijingren, whereas some speak a version of Putonghua that can only be understood by another person from Hong Kong!) Now, if English is an official language, and functioning as one of the languages of the culture, so that people write novels in it and so on, many people will learn it up to a national rather than international level. Hong Kong may be a borderline case - I don't really know; but I should have thought that here the need is for a truly international standard of competence in the language.

JLKM At this point, I would like to show you a provisional model of Hong Kong lexical usage which I drew up in collaboration with Tom McArthur in December 1997. My question is whether words such as shark-fin soup, mahjong, and kowtow can be regarded as proper English words.

MAKH Of course they are; they're used everywhere, as part of the vocabulary of English. Wherever languages come in contact, there are always exchanges of this kind; as English spread around it borrowed a great deal from local languages, either directly (like mahjong and kowtow) or via translation (like sharks-fin soup). Words like kowtow and mahjong will be found in any good English dictionary.

JLKM As more and more people become multilingual, will there, in your opinion, be more or fewer jobs for translators in the future?

MAKH I have no idea. I suspect that there will still be jobs for translators, at least in the foreseeable future, because as long as we use print or even electronic printouts, people will like to read things in their own familiar languages. However much they may become multilingual, most people will find it easier and quicker to read in their mother tongue. In most cases, if you read in your first language, you can take the book and skim quickly and you know what is in it. You have to know a foreign language very well in order to be able to do that. There are always situations in which people will prefer the texts to be in their first language. I don't think translators will be out of a job, because we are still a long way from being able, despite what is sometimes claimed, to produce really effective and cost-effective commercial machine-translation programs.

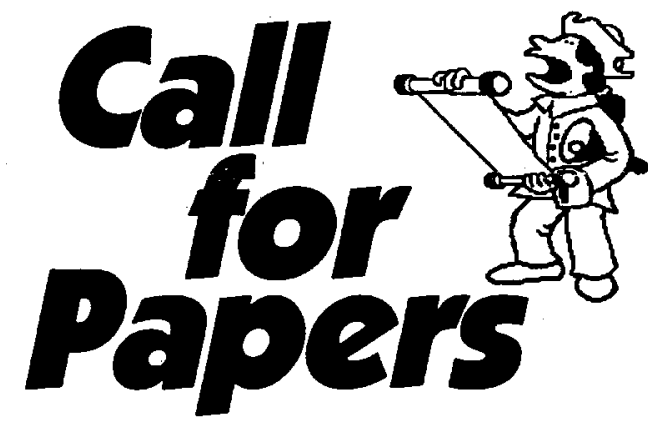

The EAIC ${ }^{\otimes}$ Clearinghouse on Languages and linguistics invites you to submit papers, reports, cumicula or other materials for inclusion in the ERIC $^{\circledR}$ database.
Submissions should be sent to:

Acquisitions Coordinator

ERIC/CL

1118 22nd Street NW

Washington DC 20037

TEL: 202-429-9292

EMAL: ERIC@CALORG 